\title{
5-Hydroxymethylcytosine discriminates between parathyroid adenoma and carcinoma
}

\author{
Elham Barazeghi ${ }^{1}$, Anthony J. Gill ${ }^{2,3}$, Stan Sidhu, ${ }^{3,4}$, Olov Norlén ${ }^{1,3,4}$, Roberto Dina ${ }^{5}$, F. Fausto Palazzo ${ }^{6}$, Per Hellman', \\ Peter Stålberg ${ }^{1}$ and Gunnar Westin ${ }^{1 *}$
}

\begin{abstract}
Background: Primary hyperparathyroidism is characterized by enlarged parathyroid glands due to an adenoma (80-85\%) or multiglandular disease ( 15\%) causing hypersecretion of parathyroid hormone (PTH) and generally hypercalcemia. Parathyroid cancer is rare (<1-5\%). The epigenetic mark 5-hydroxymethylcytosine $(5 \mathrm{hmC})$ is reduced in various cancers, and this may involve reduced expression of the ten-eleven translocation 1 (TET1) enzyme. Here, we have performed novel experiments to determine the $5 \mathrm{hmC}$ level and TET1 protein expression in 43 parathyroid adenomas (PAs) and 17 parathyroid carcinomas (PCs) from patients who had local invasion or metastases and to address a potential growth regulatory role of TET1.

Results: The global 5hmC level was determined by a semi-quantitative DNA immune-dot blot assay in a smaller number of tumors. The global $5 \mathrm{hmC}$ level was reduced in nine PCs and 15 PAs compared to four normal tissue samples $(p<0.05)$, and it was most severely reduced in the PCs. By immunohistochemistry, all 17 PCs stained negatively for $5 \mathrm{hmC}$ and TET1 showed negative or variably heterogeneous staining for the majority. All 43 PAs displayed positive $5 \mathrm{hmC}$ staining, and a similar aberrant staining pattern of $5 \mathrm{hmC}$ and TET1 was seen in about half of the PAs. Western blotting analysis of two PCs and nine PAs showed variable TET1 protein expression levels. A significantly higher tumor weight was associated to PAs displaying a more severe aberrant staining pattern of 5hmC and TET1. Overexpression of TET1 in a colony forming assay inhibited parathyroid tumor cell growth.
\end{abstract}

Conclusions: $5 \mathrm{hmC}$ can discriminate between PAs and PCs. Whether $5 \mathrm{hmC}$ represents a novel marker for malignancy warrants further analysis in additional parathyroid tumor cohorts. The results support a growth regulatory role of TET1 in parathyroid tissue.

Keywords: 5-hydroxymethylcytosine, 5hmC, Parathyroid cancer, Primary hyperparathyroidism, TET1

\section{Background}

Primary hyperparathyroidism (pHPT) is a common endocrine disease characterized by excessive secretion of PTH and increased level of serum calcium. Eighty to $85 \%$ of pHPT cases are due to a benign, single adenoma and $15 \%$ to multiglandular disease. Parathyroid carcinoma $(\mathrm{PC})$ is rare, and depending on whether it is diagnosed based on pathological examination alone or biological evidence of malignant behavior, it accounts

\footnotetext{
* Correspondence: gunnar.westin@surgsci.uu.se

'Department of Surgical Sciences, Endocrine Unit, Uppsala University, Uppsala SE-751 85, Sweden

Full list of author information is available at the end of the article
}

for less than 1 to $<5 \%$ of cases of pHPT [1-9]. An analysis of 286 PC cases from the USA revealed a 5-year survival rate of $86 \%$ and a 10-year survival rate of $49 \%$ [10]. WHO criteria for PC include demonstration of an invasive growth pattern or distant metastasis. Pathological diagnosis of PC is a challenge also because there is no widely available and completely sensitive or specific immunohistochemical marker available. Somatic inactivating mutations of CDC73/HRPT2, encoding parafibromin, are common in $\mathrm{PCs}$ defined by malignant behavior (approximately $70 \%)$ and rare $(<1 \%)$ in benign disease. Negative immunohistochemical staining for parafibromin 
has been suggested a marker for PC by some investigators but has been reported to be less useful by others [7, 11-14]. In PC patients who had local invasion and/or metastases at initial surgery or follow-up, negative staining for parafibromin was found in $64 \%$ and in $10 \%$ of patients whose diagnosis was based only on classic histological features [15].

The epigenetic mark 5-hydroxymethylcytosine $(5 \mathrm{hmC})$ was rediscovered in mammalian cells and shown to be an intermediate in DNA demethylation of 5methylcytosine. The ten-eleven translocation (TET) family of proteins (TET1, TET2, TET3) catalyze conversion of 5-methylcytosine to $5 \mathrm{hmC}$, 5-formylcytosine, and 5 -carboxylcytosine and renders passive or active DNA demethylation [16, 17]. Growing evidence suggests that $5 \mathrm{hmC}$ not only is an intermediate in DNA demethylation but also acts as an epigenetic mark that regulates gene expression by recruiting DNA-binding proteins [18]. $5 \mathrm{hmC}$ is present in many tissues and cell types and is frequently deregulated in cancer, by decreased levels of $5 \mathrm{hmC}$ when compared to normal tissues and some but not all tumors show changes in TET expression levels [19-28].

Here, we have for the first time determined levels of $5 \mathrm{hmC}$ and TET1 in PAs and PCs and investigated whether TET1 could play a role in parathyroid tumor cell growth regulation. Our study show that negative staining for $5 \mathrm{hmC}$ is a frequent event in PCs compared to PAs and suggest a novel potential marker for parathyroid malignancy. Furthermore, our data suggest that TET1 has a growth regulatory role in parathyroid tissue.

\section{Methods}

\section{Tissue specimens}

Parathyroid carcinomas $(n=17)$ from 15 patients who had local invasion and/or metastases and single parathyroid adenomas $(n=43)$ were acquired from patients diagnosed and operated on in clinical routine at the Uppsala University Hospital, Uppsala, Sweden, Department of Surgery, Royal North Shore Hospital, St Leonards, Australia, and Hammersmith Hospital, London, UK. Apparent normal parathyroid tissue $(n=4)$ was obtained as normal parathyroid gland biopsies inadvertently removed in patients subjected to parathyroidectomy. These specimens ("normals") that stained positive for parathyroid hormone (PTH), by immunohistochemistry of frozen tissue sections, were used for comparisons with parathyroid tumor tissues. Clinical data for patients with parathyroid adenoma or carcinoma are shown in Additional file 1: Table S1 and Additional file 2: Table S2, respectively. Informed consent and approval of the Uppsala Local Ethical Committee, the Northern Sydney Local Health District Human Research Ethics Committee, and by the Imperial College Research Ethics Committee, London, were achieved.

\section{DNA sampling and dot blot analysis}

Genomic DNA was extracted from frozen surgical specimens or cultured cells using DNeasy Blood and tissue kit (Qiagen $\mathrm{GmbH}$, Hilden, Germany) and paraffinembedded tissue sections using QIAamp DNA FFPE tissue kit (Qiagen $\mathrm{GmbH}$ ) according to manufacturer's instructions. 5hmC DNA standard (Zymo Research Corporation, Irvine, CA, USA) was used as a control. One microgram DNA was denatured in $0.1 \mathrm{M} \mathrm{NaOH}$ at $95{ }^{\circ} \mathrm{C}$ for $10 \mathrm{~min}$, then placed on ice and neutralized with $1 \mathrm{M}$ ammonium acetate. Twofold serial dilutions of the DNA samples were prepared and spotted onto Hybond-N+ nylon membrane (GE Healthcare, Piscataway, NJ, USA) in a Bio-Dot apparatus (Bio-Rad Laboratories, Inc., Hercules, CA, USA). The spotted membrane was fixed with UV irradiation (GS Gene Linker UV chamber, Bio-Rad), blocked with $5 \%$ skimmed milk, and incubated overnight with a rabbit polyclonal anti-5hmC antibody [19, 25, 29] (1:10K dilution, 39791; Active Motif, Carlsbad, CA, USA) and then appropriate HRP-conjugated secondary antibody. Signals were visualized with the enhanced chemiluminescence system (GE Healthcare). The same membrane was stained with $0.02 \%$ methylene blue in $0.3 \mathrm{M}$ sodium acetate to ensure equal spotting of the total DNA on the membrane. The second dot blot signal from the top for each serial dilution was used to quantify intensities by the NIH Image-J software according to the program's instructions [30] and the $5 \mathrm{hmC}$ relative intensity was calculated by dividing the value for each sample by the value of the standard. A linear relationship was obtained for the serially diluted $5 \mathrm{hmC}$ standard (not shown).

\section{Immunostaining}

Immunohistochemistry: Paraffin embedded tissue sections were deparaffinized with xylene and rehydrated through descending alcohol concentrations and distilled water. Sections were treated with $3 \%$ hydrogen peroxide and heated in EDTA pH 8.0 (Life Technologies Corporation, Carlsbad, CA, USA ), for $40 \mathrm{~min}$ with microwave at $300-\mathrm{W}$ power. The sections then were incubated with $2 \mathrm{M} \mathrm{HCl}$ for $2.5 \mathrm{~min}$ and treated with normal goat serum and the rabbit polyclonal anti-5hmC antibody (1:6000 dilution, Active Motif), rabbit polyclonal anti-TET1 (HPA019032; Prestige Antibodies, Sigma-Aldrich Sweden AB, Stockholm, Sweden) or normal horse serum and goat polyclonal anti-PTH antibody (sc-9678; Santa Cruz Biotechnology, Santa Cruz, CA, USA). The sections were washed three times with PBS, then incubated with a proper secondary antibody and $\mathrm{ABC}$ complex. $\mathrm{DAB}$ was used for visualization. Frozen tissue sections (apparent normal parathyroid tissue and parathyroid carcinoma \#12 and \#13) were first fixed in formalin and then stained as described above but excluding incubation in $2 \mathrm{M} \mathrm{HCl}$. 
Immunofluorescence: The sections were treated and incubated with rabbit polyclonal anti-5hmC antibody (1:6000 dilution, Active Motif) as mentioned above, then washed three times with PBS (0.05\% Tween20) and incubated with proper fluorescence secondary antibody (Alexa 594, Life Technologies). Sections were washed again and mounted with Vectashield with Dapi (Vector Laboratories, Inc., Burlingame, CA, USA). Normal liver tissue was used as positive control for TET1.

\section{Western blotting}

Protein extracts prepared using Cytobuster Protein Extract Reagent (Merck Millipore, Billerica, MA, USA) with complete protease inhibitor cocktail (Roche Diagnostics Scandinavia AB, Bromma, Sweden). Rabbit polyclonal anti-TET1 (GTX124207; GeneTex Inc, Irvine, CA, USA) and goat polyclonal anti-Actin (sc-1616; Santa Cruz Biotechnology) were used. After incubation with the appropriate secondary antibody, bands were visualized using the enhanced chemiluminescence system (GE Healthcare).

\section{Colony formation assay and measurement of apoptosis} sHPT-1 parathyroid tumor cells [31] were distributed onto $35-\mathrm{mm}$ dishes $\left(2 \times 10^{5}\right)$ in DMEM/10 \% fetal bovine serum (Sigma) and transfected in triplicates with $1 \mu \mathrm{g}$ pIRES-hrGFP ll-TET1-FL [32] or empty vector (pIRES-hrGFP ll) using FuGENE 6 transfection reagent (Promega Biotech AB, Nacka, Sweden), according to manufacturer's instructions. Twenty four hours after transfection, 2000 sHPT-1 cells were distributed onto six-well plates in triplicates. After additional $24 \mathrm{~h}$, a fresh medium with $0.2 \mathrm{mg} / \mathrm{ml}$ Neomycin (G418, SigmaAldrich) was added and refreshed every $72 \mathrm{~h}$. After 10-day selection in Neomycin, the cells were fixed with $10 \%$ acetic acid $/ 10 \%$ methanol and stained with $0.4 \%$ crystal violet, and visible colonies were counted. HEK293T cells $\left(1.5 \times 10^{6}\right)$ were transfected with FuGENE 6 transfection reagent (Promega Biotech AB). After $24 \mathrm{~h}, 8000$ HEK293T cells were distributed onto six-well plates in triplicates and the next day $0.2 \mathrm{mg} / \mathrm{ml}$ Neomycin was added to culture medium. After 10 days in selection cells were fixed, stained and counted as described above. Successful transfection was determined by real-time quantitative RT-PCR and western blotting for sHPT-1 and HEK293T, after $72 \mathrm{~h}$. The human parathyroid tumor cell line sHPT-1 was used at cell passages 18-30, and the cells were routinely tested for PTH expression by immunostaining of cultured fixed cells [31]. The human embryonic kidney cell line HEK293T was obtained from ATCC (LGC, Promochem, Sweden) and used at cell passages 10-30. Apoptosis was measured in sHPT-1 cells $72 \mathrm{~h}$ after transfection and after 10 days of antibiotic selection, using the Cell Death Detection ELISA kit (Roche Molecular Biochemicals, Mannheim, Germany), according to the manufacturer's instructions. As a positive control, cells were incubated with $0.1 \mu \mathrm{g} / \mathrm{ml}$ camptothecin (Sigma-Aldrich) for $72 \mathrm{~h}$. Transfected cells were also incubated with FITC-labeled annexin V and propidium iodide (Sigma-Aldrich) and analyzed by flow cytometry on a FACS Canto II (BD Biosciences). Annexin V-FITC binds to phosphatidylserine translocated to the external portion of the membrane as a marker of apoptosis, and propidium iodide distinguishes dead cells with ruptured membrane.

\section{Real-time quantitative PCR}

DNA-free total RNA was extracted using RNeasy Plus Mini kit (Qiagen $\mathrm{GmbH}$ ) according to manufacturer's instructions and successful treatment with DNase I of all RNA preparations using TURBO DNA-free ${ }^{\mathrm{Tm}}$ kit (Life Technologies Corporation) was established by PCR analysis. After reverse transcription of RNA preparations with random hexamer primers using First-strand complementary DNA (cDNA) synthesis kit (GE Healthcare), realtime quantitative RT-PCR was performed on StepOnePlus RealTime PCR systems (Life Technologies Corporation) using TaqMan gene expression Master Mix and assays for TET1 transcript (Hs00286756_m1) and GAPDH (Hs02758991_g1). Each cDNA sample was analyzed in triplicate.

\section{Statistical analysis}

ANOVA test was used to calculate differences in relative $5 \mathrm{hmC}$ level between the three biological groups and to compare clinical data between the four groups of adenomas. Bonferroni test was used to adjust the $p$ values (due to having a few number of samples, Kruskal-Wallis test was used to check the significance of the $p$ values obtained from the ANOVA test). Differences in colony formation assay and real-time quantitative RT-PCR was evaluated using unpaired $t$ test, and data are presented as mean \pm SEM. Statistical analysis was performed using $\mathrm{R}$ version 3.1.1 (2014-07-10). $p<0.05$ was considered significant.

\section{Results}

Reduced global level of 5-hydroxymethylcytosine in parathyroid tumors

A DNA immune-dot blot assay was established using a previously validated rabbit polyclonal anti- $5 \mathrm{hmC}$ antibody $[19,25,29]$. Comparisons of twofold serial dilutions of total DNA isolated from PCs $(n=9)$, PAs $(n=15)$, and apparent normal parathyroid biopsies $(n=4)$ revealed a significantly $(p<0.05)$ reduced level of $5 \mathrm{hmC}$ in the adenomas and the carcinomas compared to the normal tissue samples (Fig. 1a, b). The global $5 \mathrm{hmC}$ level was most severely reduced in the PCs. 



Fig. 1 DNA immune-dot blot assay of 5hmC using a rabbit polyclonal anti-5hmC antibody. a Analysis of twofold serial dilutions of DNA. Standard (control 5hmC-DNA), normal parathyroid tissue specimens $(n=4)$, PAs $(n=15)$, and PCs $(n=9)$. MB methylene blue loading control represents the least diluted DNA sample. $\mathbf{b}$ Quantification of the results in $\mathbf{a} .{ }^{*} p<0.05$ 


\section{Immunohistochemistry of $5 \mathrm{hmC}$ discriminates between adenoma and carcinoma}

Additional PCs were available for immunohistochemical analysis. In comparison to normal parathyroid cells that stained positively, all 17 analyzed carcinomas from 15 patients stained negatively for $5 \mathrm{hmC}$ (Fig. 2 and Additional file 3: Table S3, denoted, - negative, undetectable). These results are in line with those obtained from the DNA immune-dot blot assay, where the global $5 \mathrm{hmC}$ level was very low to almost undetectable in the analyzed PCs (Fig. 1a, b).

In contrast, the observed staining patterns of the adenomas were generally heterogeneous with different appearances and these were denoted with $M$ (mosaic, a mixture of positive and negative cells); $\mathrm{VH}$ (variable heterogeneous, areas with positive staining together with areas of negative staining, and + (almost all cells stained positive regardless of strength). The results are summarized in Additional file 3: Table S4-S7 and representative staining patterns are shown in Fig. 3a, b. Overall, 7 adenomas showed positive staining for almost all cells (+, Additional file 3: Table S4) and 36 PAs stained positively for $5 \mathrm{hmC}$ but with the aberrant variable appearance described above. Of the 36 PAs with aberrant variable appearance of $5 \mathrm{hmC}, 23$ adenomas showed mosaic staining $(\mathrm{M})$ with a mixture of positive and negative cells (Additional file 3: Table S4-S6), 6 adenomas showed mosaic staining $(\mathrm{M})$ together with variable heterogeneity $(\mathrm{VH})$, areas of positive staining together with areas of negative staining (Additional file 3: Table S6), and 7 adenomas showed $\mathrm{VH}$ only (Additional file 3: Table S7). The presence of $5 \mathrm{hmC}$ negatively staining cells in PAs is consistent with the observed reduction of the global $5 \mathrm{hmC}$ level by the DNA immune-dot blot assay (Fig. 1a, b). Also, three PAs (\#22, 24, 29) that stained positive for almost all cells regardless of strength (+, Additional file 3: Table S4) showed reduced global 5hmC level (Fig. 1a).

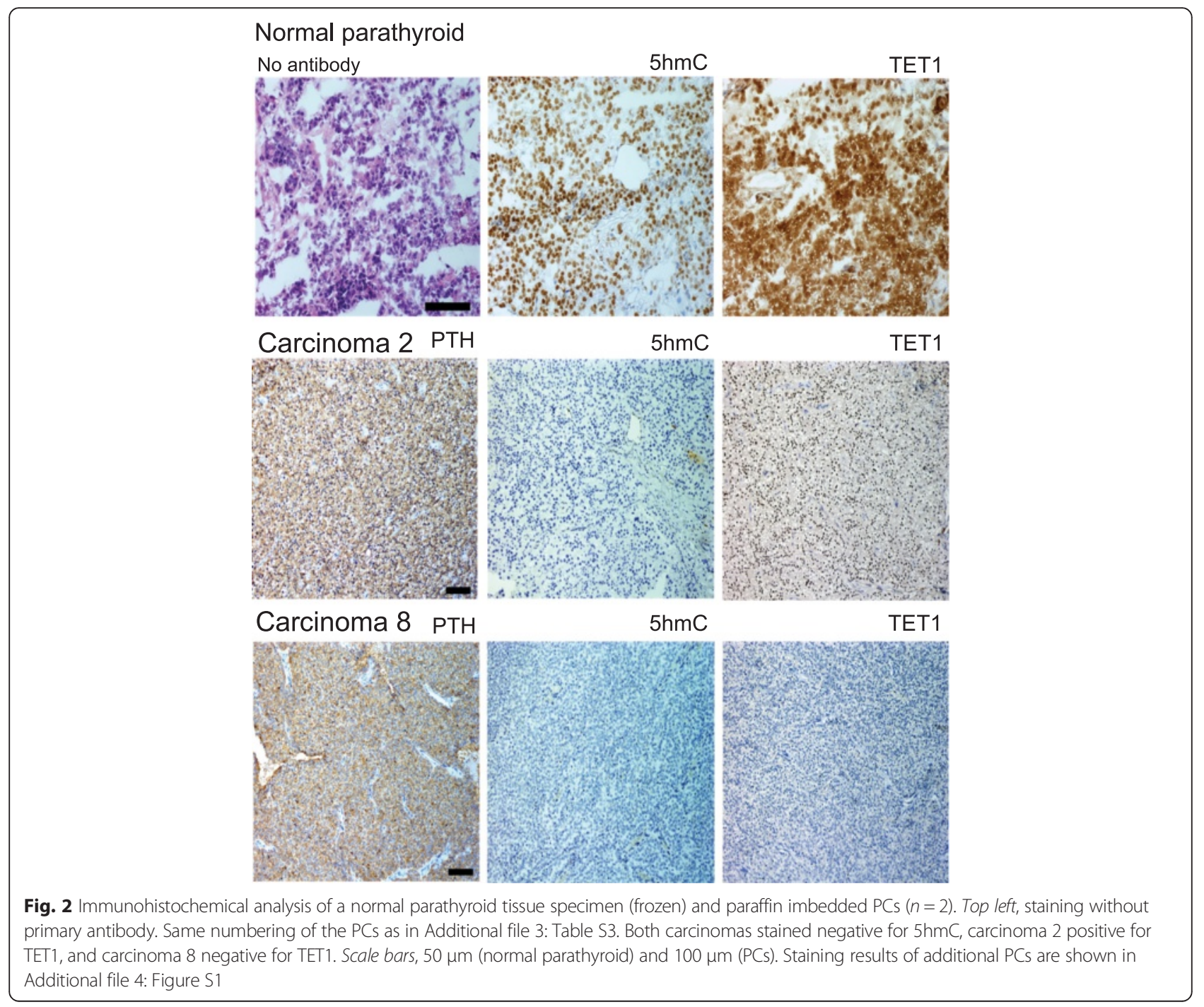




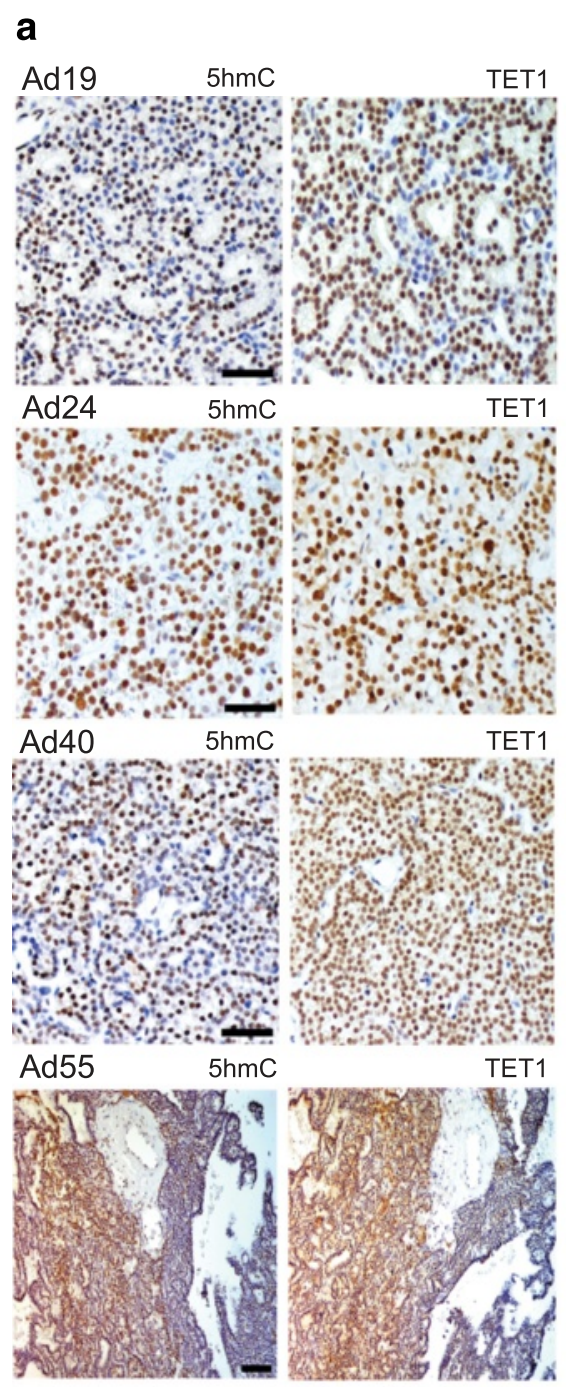

b

Ad53


Fig. 3 (See legend on next page.) 
(See figure on previous page.)

Fig. 3 a Representative results from immunohistochemical analysis of $5 \mathrm{hmC}$ and TET1 in PAs $(n=4)$. Ad19 shows mosaic staining (M) for both (a mixture of positive and negative cells), Ad24 shows + (almost all cells stained positive regardless of strength), Ad40 shows M for 5hmC and + for TET1, and Ad55 shows VH (variable heterogeneous, areas with positive staining together with areas of negative staining). Scale bars, 50 um (Ad 19, Ad24, Ad40) and $100 \mu \mathrm{m}$ (Ad55). b Immunofluorescence was applied to demonstrate typical appearance of mosaic staining (M) of 5hmC at two magnifications: a scale bar $100 \mu \mathrm{m}$; b scale bar $50 \mu \mathrm{m}$

To summarize, all 17 PCs showed negative/undetectable staining for $5 \mathrm{hmC}$ and all $43 \mathrm{PAs}$ contained $5 \mathrm{hmC}$ positive cells. $5 \mathrm{hmC}$ may therefore be used as a marker to discriminate between benign and malignant parathyroid tumors.

TET1 expression and $5 \mathrm{hmC}$ level establish groups of PAs and relate to tumor weight

TET protein family members are responsible for the conversion of $5 \mathrm{mC}$ to $5 \mathrm{hmC}$ (16) and altered $5 \mathrm{hmC}$ levels may be caused by deregulated TET expression [26-28]. We therefore performed immunohistochemical analysis of TET1 in our cohort of PAs and PCs (Additional file 3: Table S3-S7, Figs. 2 and 3a). The observed staining patterns of TET1 resembled those of 5hmC. TET1 expression was undetectable in 7 out of the 17 PCs (Additional file 3: Table S3), variable heterogeneous $(\mathrm{VH})$, with areas of positive staining together with areas of negative staining, was seen in 6 carcinomas, and 4 carcinomas showed positive staining in most cells, regardless of strength $(+)$. A primary PC and

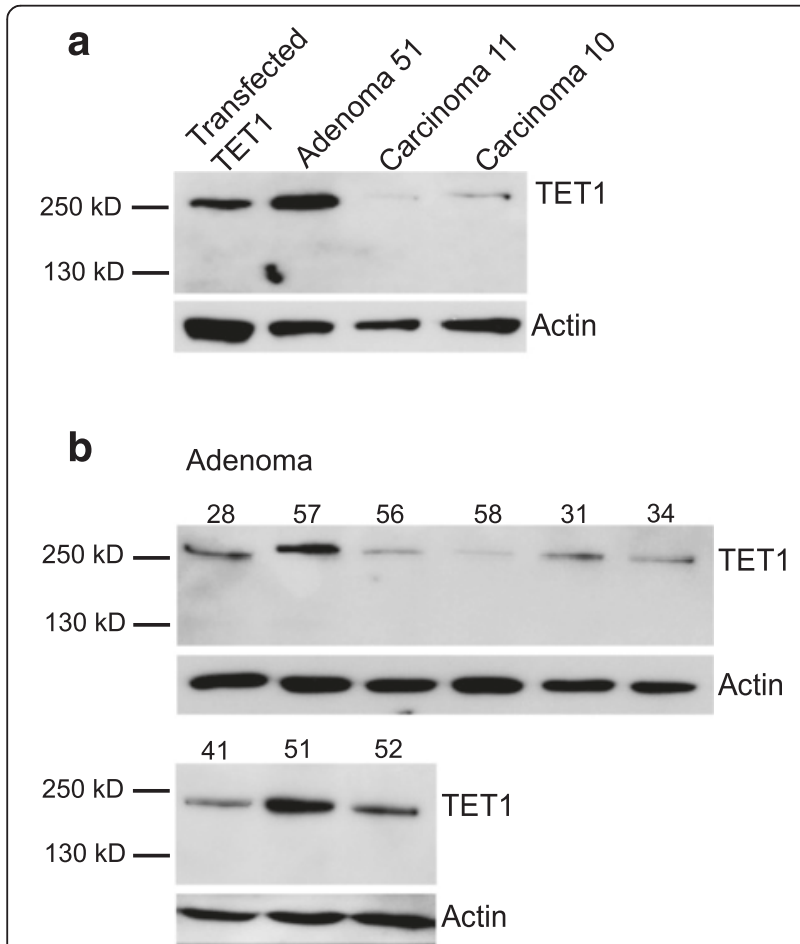

Fig. 4 Western blotting analysis of TET1. a Transfected TET1 (SHPT-1 cells), PA51, PC11, and PC 10. b PAs $(n=9)$ metastasis from the same patient were available for analysis and showed the same staining patterns of $5 \mathrm{hmC}$ and TET1 (Additional file 3: Table S3, tumor nos. 14 and 15). The staining for TET1 in the PCs and PAs was nuclear or nuclear/cytoplasmic, with no associations to overall staining patterns (+, M, VH, data not shown). Staining for parafibromin, encoded by HRPT2, was available for PC nos. 1-9. No associations of negative or positive parafibromin staining to TET1 expression $(-,+$, $\mathrm{VH}$ ) were observed (Additional file 2: Table S2 and Additional file 3: Table S3). The staining results for $5 \mathrm{hmC}$ and TET1 were used to group the analyzed PAs as presented in Additional file 3: Tables S4-S7. Additional file 3: Table S4 presents tumors with analogous mosaic staining $(\mathrm{M})$ of both $5 \mathrm{hmC}$ and TET1 and tumors with positive staining of $5 \mathrm{hmC} / \mathrm{TET} 1$ for almost all cells regardless of strength $(+)$. Additional file 3: Table S5 contains PAs with mosaic (M) appearance of $5 \mathrm{hmC}$ and positive staining of TET1 for almost all cells regardless of strength (+). Additional file 3: Tables S6 and S7 present adenomas with more severe aberrant staining patterns. Mosaic (M) staining for $5 \mathrm{hmC}$ together with $\mathrm{VH}$ (variable heterogeneous, with areas of positive staining together with areas of negative staining, Additional file 3: Table S6) or analogous VH appearance

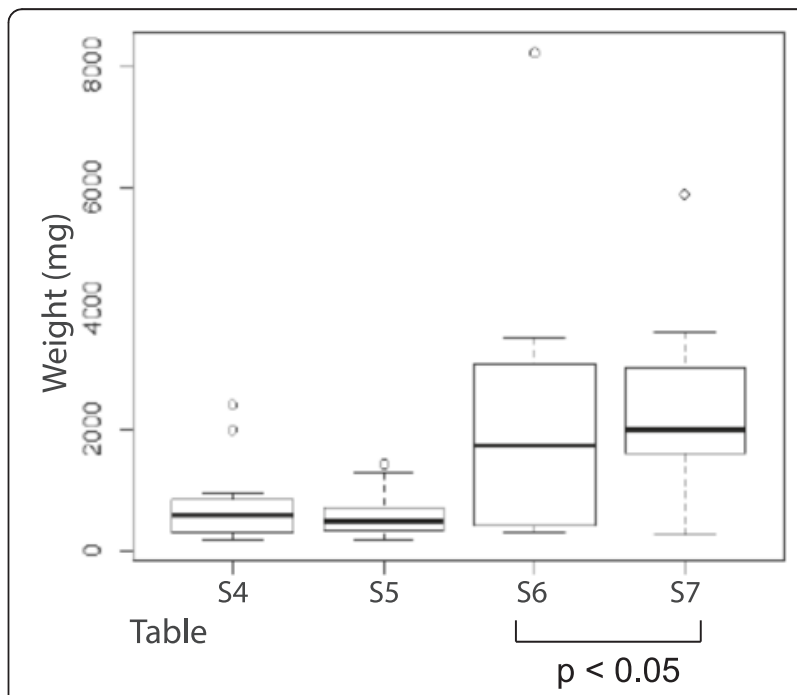

Fig. 5 Association of PAs of Additional file 3: Table S6 and S7 to tumor weight (and not to serum PTH, serum calcium or age). These PAs showed a more severe aberrant staining pattern of $5 \mathrm{hmC}$ and TET1 $(\mathrm{M}, \mathrm{VH})$. Clinical data is presented in Additional file 1: Table S1 


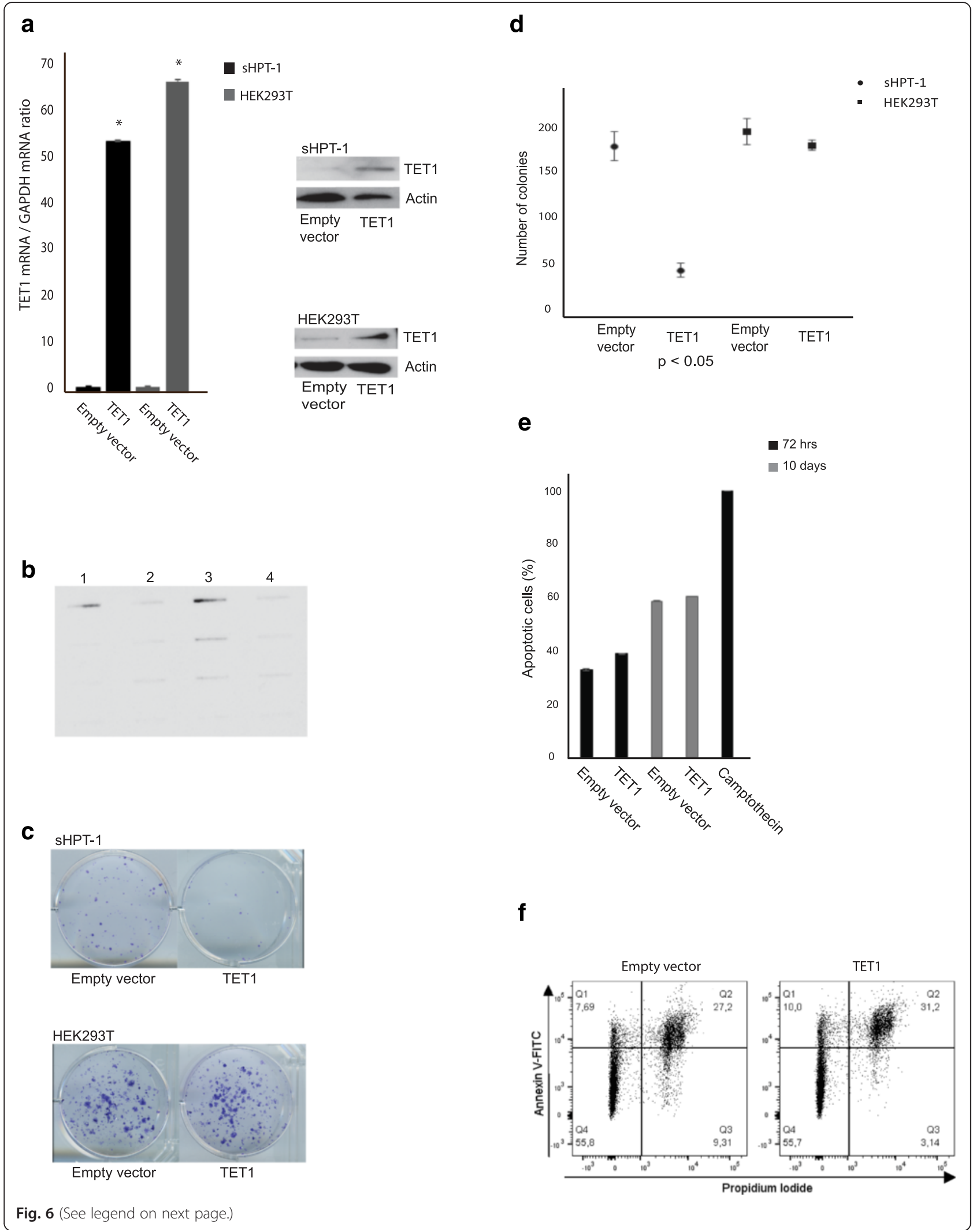




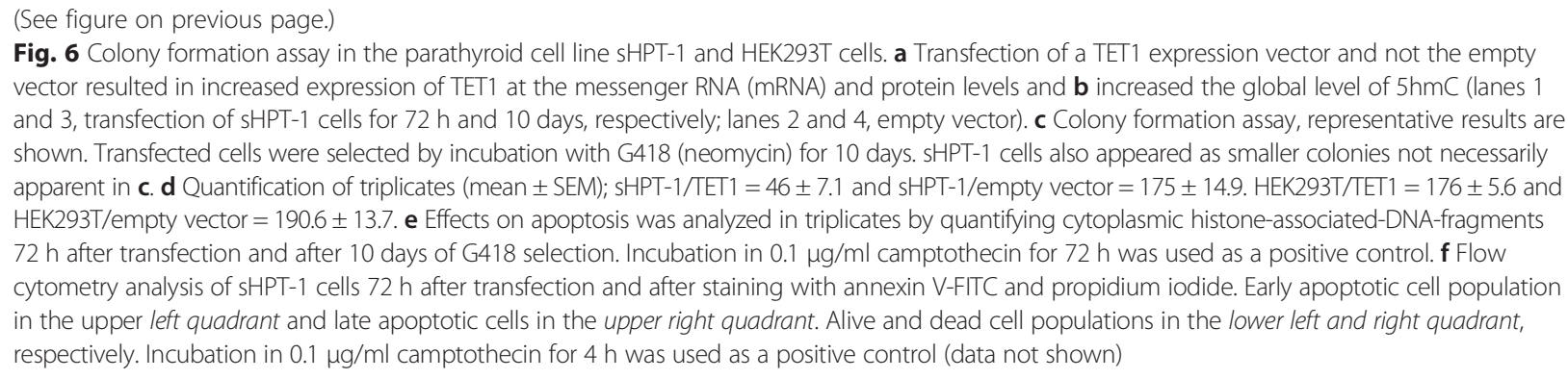

for 5hmC and TET1 (Additional file 3: Table S7). All PAs showed positive TET1 staining but with a similar aberrant staining pattern $(\mathrm{M}, \mathrm{VH})$ of TET1 and $5 \mathrm{hmC}$ in about half of the PAs. PTH expression was evident also in areas of negative $5 \mathrm{hmC}$ and TET1 staining (data not shown). Western blotting analysis was also done for TET1 and showed very low expression levels in the two analyzed PCs (Fig. 4a) and low to variable expression levels in the nine analyzed adenomas (Fig. 4b). When clinical parameters (Additional file 1: Table S1) of the patients (serum PTH, serum calcium, tumor weight, age) were related to the staining results of the different PA groups (Additional file 3: Table S4-S7), PAs of Additional file 3: Table S6 and S7 was found to be associated with a higher tumor weight (Fig. 5). Thus, a more severe aberrant staining pattern of $5 \mathrm{hmC}$ and TET1 associated to tumor mass and may therefore interfere with the tumor cell growth regulatory control.

\section{A growth regulatory role of TET1 in parathyroid cells}

In order to test experimentally whether TET1 could interfere with parathyroid cellular growth, the parathyroid tumor cell line sHPT-1 and also HEK293T cells were transfected with a TET1 expression vector or empty vector in a colony formation assay. Increased expression of TET1 and increased level of $5 \mathrm{hmC}$ were detected after transfection (Fig. 6a, b), and this resulted in a significant reduced number and also size of sHPT-1 cell colonies (Fig. 6c, d). This was caused by reduced growth capability as no effect on apoptosis was detected after transfection of TET1 to sHPT-1 cells, as determined by quantifying cytoplasmic histone-associatedDNA-fragments and by flow cytometry of cells stained with annexin V-FITC and propidium iodide (Fig. 6e, f). No growth inhibitory effect was seen in HEK293T cells (Fig. 6c, d). Overall, these results strongly support a growth regulatory role of TET1 in parathyroid tumor cells.

\section{Discussion}

PC is difficult to diagnose; it has been reported that up to half of metastatic or recurrent PCs were first diagnosed as benign [33]. Correct diagnosis may suggest aggressive surgery to decrease the risk of recurrence. Several immunohistochemical markers of parathyroid malignancy have been suggested (e.g., APC, galectin-3, parafibromin, PGP9.5, Rb), but none has been widely accepted as highly sensitive and specific [7, 9]. Our novel results demonstrated that all 17 analyzed PCs stained negatively for $5 \mathrm{hmC}$. In contrast, all 43 adenomas showed positive staining for $5 \mathrm{hmC}$. Thus, it seems that $5 \mathrm{hmC}$ can discriminate between PAs and PCs. We suggest that negative staining for $5 \mathrm{hmC}$ may present a novel potential marker for parathyroid malignancy and that this warrants investigations in additional cohorts of parathyroid tumors from patients with pHPT.

TET1 was first identified as a fusion partner of the mixed lineage leukemia $(M L L)$ gene in acute myeloid leukemia, and it is now clear that TET1 plays an essential oncogenic role in MLL-rearranged leukemia [27, 28, 34]. On the contrary, in many solid tumors, including breast, lung, prostate, and colorectal, TET1 expression is downregulated with reduced levels of $5 \mathrm{hmC}$, and TET1 mutations are rarely observed [22, 26-28]. TET1 has been shown to play a role as tumor suppressor in breast, prostate, and colon cancers [35-37].

We found that expression of TET1 was undetectable in 7 out of the 17 PCs (41\%) and in 6 PCs the expression of TET1 was heterogeneous with areas of positive cells together with areas of negative cells. Since a clear correlation between decreased $5 \mathrm{hmC}$ levels and TET1 expression was observed only in $41 \%$ of the PCs, other mechanisms must be involved. Besides indirect mechanisms, it is possible that TET2 also contributes to the observed reduced levels of $5 \mathrm{hmC}$ in some of the analyzed tumors [26, 28]. This will be addressed in future experiments when an appropriate antibody to TET2 is available.

A significantly higher tumor weight was found associated to PAs that displayed a more severe aberrant staining pattern of $5 \mathrm{hmC}$ and TET1. This strongly suggests a growth regulatory role of $5 \mathrm{hmC}$ and TET1. Consistently, overexpression of TET1 resulted in inhibition of parathyroid tumor cell growth. These observations support a possible role of TET1 as a tumor suppressor gene in this tissue. 
Reduced expression of TET1 is expected to result in direct deregulation of parathyroid target genes, as for example described in colon cancer for the DKK3 and DKK4 inhibitors of the WNT pathway [37]. Interestingly, impaired expression of another inhibitor of the WNT signaling pathway by DNA methylation, the tumor suppressor protein APC (adenomatous polyposis coli), has been associated with PC malignancy $[38,39]$.

\section{Conclusions}

$\mathrm{PC}$ is very rare, and in the absence of disseminated disease, it is sometimes difficult to distinguish PC from benign adenoma. At present, a widely available and sensitive or specific immunohistochemical marker for PC is not available. Here, we have analyzed a relatively large number of PCs and found $5 \mathrm{hmC}$ to present a new potential negative marker for parathyroid malignancy. Our novel findings also include an association of a more aberrant immunohistochemical staining pattern of $5 \mathrm{hmC}$ and TET1 to tumor weight for the PAs and a direct demonstration in vitro of a growth regulatory role for TET1 in parathyroid tumor cells.

\section{Additional files}

Additional file 1: Table S1. Clinical data (serum PTH, serum calcium, tumor weight, age) for patients with parathyroid adenoma. (EPS 3563 kb)

Additional file 2: Table S2. Clinical data for patients with parathyroid carcinoma. Tumor nos. 1-9, 13, 14, 16, and 17 present primary PCs and 10-12 and 15 metastases. Tumor nos. 10 and 11 and 14 and 15 were from the same patient, respectively. The following five PCs have been published previously. Tumor no. 3 [13], no. 4 [40], and no. 11-13 [41]. Negative staining for parafibromin was detected in PC nos. 2, 3, and 5-8 and positive staining in nos. 1, 4, and 9 (unpublished results). (EPS 1549 kb)

Additional file 3: Tables S3-S7. Table S3. $I H C$ results for carcinomas. Table S4-S7. IHC results for adenomas. (EPS $3060 \mathrm{~kb}$ )

Additional file 4: Figure S1. A, Immunohistochemical analysis of $5 \mathrm{hmC}$ and TET1 in paraffin imbedded PCs. Scale bar, $100 \mu \mathrm{m}$. All PCs stained positive for PTH (not shown). Same numbering of the PCs as in Additional file 3: Table S3. Carcinoma nos. 2 and 8 are shown in Fig. 2. B, Normal liver tissue was used as positive control and stained with or without the primary TET1 antibody. Clear TET1 nuclear staining was observed only in the presence of the primary antibody. Scale bar, $100 \mu \mathrm{m}$. (EPS $324013 \mathrm{~kb}$ )

\section{Competing interests}

The authors declare that they have no competing interests.

\section{Authors' contributions}

EB performed laboratory experiments and statistical analyses, interpreted the results, and participated in writing of the manuscript. AJG, SS, RD, and FFP provided tissue samples and interpreted the results. $\mathrm{ON}$ and $\mathrm{PH}$ interpreted the results and revised the manuscript. PS participated in the study design and coordination and revised the manuscript. GW conceived of the study, participated in its design and coordination, and helped to draft the manuscript. All authors read and approved the final manuscript.

\section{Acknowledgements}

This study has been supported by grants from The Swedish Cancer Society, Lions Fund for Cancer Research, and Erik, Karin o Gösta Selanders Stiftelse. We thank Olof Berggren for the help with the flow cytometry experiment.

\section{Author details}

'Department of Surgical Sciences, Endocrine Unit, Uppsala University, Uppsala SE-751 85, Sweden. ${ }^{2}$ Department of Anatomical Pathology, Royal North Shore Hospital, Pacific Highway, St Leonards, NSW 2065, Australia. ${ }^{3}$ University of Sydney, Sydney, NSW 2006, Australia. ${ }^{4}$ Department of Surgery, Royal North Shore Hospital, Pacific Highway, St Leonards, NSW 2065,

Australia. ${ }^{5}$ Department of Histopathology, Hammersmith Hospital, Imperial College, London, UK. 'Endocrine Surgery, Hammersmith Hospital, Imperial College, London, UK.

Received: 12 October 2015 Accepted: 2 March 2016 Published online: 12 March 2016

\section{References}

1. Sandelin K, Auer G, Bondeson L, Grimelius L, Farnebo LO. Prognostic factors in parathyroid cancer: a review of 95 cases. World J Surg. 1992;16:724-31.

2. Favia G, Lumachi F, Polistina F, D'Amico DF. Parathyroid carcinoma: sixteen new cases and suggestions for correct management. World J Surg. 1998;22:1225-30.

3. Lee PK, Jarosek SL, Virnig BA, Evasovich M, Tuttle TM. Trends in the incidence and treatment of parathyroid cancer in the United States. Cancer. 2007:109:1736-41.

4. Westin G, Björklund P, Åkerström G. Molecular genetics of parathyroid disease. World J Surg. 2009;33:2224-33.

5. Sharretts JM, Simonds WF. Clinical and molecular genetics of parathyroid neoplasms. Best Pract Res Clin Endocrinol Metab. 2012;24:491-02.

6. Al-Kurd A, Mekel M, Mazeh H. Parathyroid carcinoma. Surg Oncol. 2014:23:107-14

7. Gill AJ. Understanding the genetic basis of parathyroid carcinoma. Endocr Pathol. 2014:25:30-4.

8. Shifrin A, LiVolsi V, Shifrin-Douglas S, Zheng M, Erler B, Matulewicz T, et al. Primary and metastatic parathyroid malignancies: a rare or underdiagnosed condition? J Clin Endocrinol Metab. 2015;100:E478-81.

9. Duan K, Mete Ö. Parathyroid carcinoma: diagnosis and clinical implications. Turk Patoloji Derg. 2015;31 Suppl 1:80-97.

10. Hundahl SA, Fleming ID, Fremgen AM, Menck HR. Two hundred eighty-six cases of parathyroid carcinoma treated in the U.S. between 1985-1995: a national cancer data base report. The American College of Surgeons Commission on Cancer and the American Cancer Society. Cancer. 1999;86:538-44

11. Carpten JD, Robbins CM, Villablanca A, Forsberg L, Presciuttini S, Bailey-Wilson J, et al. HRPT2, encoding parafibromin, is mutated in hyperparathyroidism-jaw tumor syndrome. Nat Genet. 2002;32:676-80.

12. Shattuck TM, Välimäki S, Obara T, Gaz RD, Clark OH, Shoback D, et al. Somatic and germ-line mutations of the HRPT2 gene in sporadic parathyroid carcinoma. N Engl J Med. 2003;349:1722-29.

13. Gill AJ, Clarkson A, Gimm O, Keil J, Dralle H, Howell VM, et al. Loss of nuclear expression of parafibromin distinguishes parathyroid carcinomas and hyperparathyroidism-jaw tumor (HPT-JT) syndrome-related adenomas from sporadic parathyroid adenomas and hyperplasias. Am J Surg Pathol. 2006;30:1140-49.

14. Juhlin CC, Villablanca A, Sandelin K, Haglund F, Nordenström J, Forsberg L, et al. Parafibromin immunoreactivity: its use as an additional diagnostic marker for parathyroid tumor classification. Endocr Relat Cancer. 2007:14:501-12

15. Cetani F, Banti C, Pardi E, Borsari S, Viacava P, Miccoli P, et al. CDC73 mutational status and loss of parafibromin in the outcome of parathyroid cancer. Endocr Connect. 2013;2:186-95

16. Tahiliani M, Koh KP, Shen Y, Pastor WA, Bandukwala H, Brudno Y, et al. Conversion of 5-methylcytosine to 5-hydroxymethylcytosine in mammalian DNA by MLL partner TET1. Science. 2009;324:930-35.

17. Ito S, Shen L, Dai Q, Wu SC, Collins LB, Swenberg JA, et al. Tet proteins can convert 5-methylcytosine to 5-formylcytosine and 5-carboxylcytosine. Science. 2011;333:1300-03.

18. Spruijt CG, Gnerlich F, Smits AH, Pfaffeneder T, Jansen PW, Bauer C, et al. Dynamic readers for 5 -(hydroxy)methylcytosine and its oxidized derivatives. Cell. 2013;152:1146-59.

19. Haffner MC, Chaux A, Meeker AK, Esopi DM, Gerber J, Pellakuru LG, et al. Global 5-hydroxymethylcytosine content is significantly reduced in tissue stem/progenitor cell compartments and in human cancers. Oncotarget. 2011;2:627-37. 
20. Jin SG, Jiang Y, Qiu R, Rauch TA, Wang Y, Schackert G, et al. 5-Hydroxymethylcytosine is strongly depleted in human cancers but its levels do not correlate with IDH1 mutations. Cancer Res. 2011;71:7360-65.

21. Kraus TF, Globisch D, Wagner M, Eigenbrod S, Widmann D, Münzel M, et al. Low values of 5-hydroxymethylcytosine ( $5 \mathrm{hmC}$ ), the "sixth base," are associated with anaplasia in human brain tumors. Int J Cancer. 2012;131:1577-90.

22. Kudo Y, Tateishi K, Yamamoto K, Yamamoto S, Asaoka Y, ljichi H, et al. Loss of 5-hydroxymethylcytosine is accompanied with malignant cellular transformation. Cancer Sci. 2012;103:670-76.

23. Lian CG, Xu Y, Ceol C, Wu F, Larson A, Dresser K, et al. Loss of 5-hydroxymethylcytosine is an epigenetic hallmark of melanoma. Cell. 2012;150:1135-46.

24. Liu C, Liu L, Chen X, Shen J, Shan J, Xu Y, et al. Decrease of 5-hydroxymethylcytosine is associated with progression of hepatocellular carcinoma through downregulation of TET1. PLoS One. 2013;8:e62828.

25. Yang H, Liu Y, Bai F, Zhang JY, Ma SH, Liu J, et al. Tumor development is associated with decrease of TET gene expression and 5-methylcytosine hydroxylation. Oncogene. 2013;32:663-9.

26. Huang Y, Rao A. Connections between TET proteins and aberrant DNA modification in cancer. Trends Genet. 2014;30:464-74.

27. Kroeze LI, van der Reijden BA, Jansen JH. 5-Hydroxymethylcytosine: an epigenetic mark frequently deregulated in cancer. Biochim Biophys Acta. 1855;2015:144-54

28. Scourzic L, Mouly E, Bernard OA. TET proteins and the control of cytosine demethylation in cancer. Genome Med. 2015;7:9.

29. labal K, Jin SG, Pfeifer GP, Szabó PE. Reprogramming of the paternal genome upon fertilization involves genome-wide oxidation of 5-methylcytosine. Proc Natl Acad Sci U S A. 2011;108:3642-47.

30. Huang $\mathrm{N}$, Tan L, Xue Z, Cang J, Wang $\mathrm{H}$. Reduction of DNA hydroxymethylation in the mouse kidney insulted by ischemia reperfusion. Biochem Biophys Res Commun. 2012:422:697-02.

31. Björklund P, Åkerström G, Westin G. Activated beta-catenin in the novel human parathyroid tumor cell line sHPT-1. Biochem Biophys Res Commun. 2007; 352:532-36

32. Jin C, Lu Y, Jelinek J, Liang S, Estecio MR, Barton MC, et al. TET1 is a maintenance DNA demethylase that prevents methylation spreading in differentiated cells. Nucleic Acids Res. 2014:42:6956-71.

33. Sandelin K, Tullgren O, Farnebo LO. Clinical course of metastatic parathyroid cancer. World J Surg. 1994;18:594-8.

34. Huang H, Jiang X, Li Z, Li Y, Song CX, He C, et al. TET1 plays an essential oncogenic role in MLL-rearranged leukemia. Proc Natl Acad Sci U S A. 2013:110:11994-99.

35. Hsu CH, Peng KL, Kang ML, Chen YR, Yang YC, Tsai CH, et al. TET1 suppresses cancer invasion by activating the tissue inhibitors of metalloproteinases. Cell Rep. 2012;2:568-79.

36. Sun $M$, Song CX, Huang $H$, Frankenberger CA, Sankarasharma D, Gomes $S$, et al. HMGA2/TET1/HOXA9 signaling pathway regulates breast cancer growth and metastasis. Proc Natl Acad Sci U S A. 2013;110:9920-25.

37. Neri F, Dettori D, Incarnato D, Krepelova A, Rapelli S, Maldotti M, et al. TET1 is a tumour suppressor that inhibits colon cancer growth by derepressing inhibitors of the WNT pathway. Oncogene. 2015;34:4168-76.

38. Juhlin CC, Haglund F, Villablanca A, Forsberg L, Sandelin K, Bränström R, et al. Loss of expression for the Wnt pathway components adenomatous polyposis coli and glycogen synthase kinase 3-beta in parathyroid carcinomas. Int J Oncol. 2009;34:481-92.

39. Svedlund J, Aurén M, Sundström M, Dralle $H$, Åkerström G, Björklund P, Westin G. Aberrant WNT/ $\beta$-catenin signaling in parathyroid carcinoma. Mol Cancer. 2010;9:294

40. Grodski S, Gill A, Robinson BG, Sidhu S. Nonfunctioning parathyroid cancer presenting as a cervical mass. Thyroid. 2008;18:473-4.

41. Svedlund J, Barazeghi E, Stålberg P, Hellman P, Åkerström G, Björklund P, Westin $\mathrm{G}$. The histone methyltransferase $\mathrm{EZH} 2$, an oncogene common to benign and malignant parathyroid tumors. Endocr Relat Cancer. 2014;21: 231-9.

\section{Submit your next manuscript to BioMed Central and we will help you at every step:}

- We accept pre-submission inquiries

- Our selector tool helps you to find the most relevant journal

- We provide round the clock customer support

- Convenient online submission

- Thorough peer review

- Inclusion in PubMed and all major indexing services

- Maximum visibility for your research

Submit your manuscript at www.biomedcentral.com/submit

) Biomed Central 